\title{
Graphene Nanoplatelets-Based Ni-Zeolite Composite Catalysts for Heptane Hydrocracking
}

\author{
Roba Saab ${ }^{1}$, Kyriaki Polychronopoulou ${ }^{1,2, *} \mathbb{D}$, Nikolaos Charisiou ${ }^{3}$, Maria A. Goula ${ }^{3}[$ and \\ Andreas Schiffer 1,*(D) \\ 1 Department of Mechanical Engineering, Khalifa University of Science and Technology, \\ Abu Dhabi 127788, UAE; roba.saab@ku.ac.ae \\ 2 Center for Catalysis and Separation, Khalifa University of Science and Technology, Abu Dhabi 127788, UAE \\ 3 Department of Chemical Engineering, University of Western Macedonia, 50100 Koila Kozani, Greece; \\ ncharis@teikoz.gr (N.C.); mgoula@teiwm.gr (M.A.G.) \\ * Correspondence: kyriaki.polychrono@ku.ac.ae (K.P.); andreas.schiffer@ku.ac.ae (A.S.); \\ Tel.: +971-(0)2-401-8211 (K.P.); +971-(0)2-401-8204 (A.S.)
}

Received: 27 April 2020; Accepted: 14 May 2020; Published: 18 May 2020

\begin{abstract}
This paper examines the effect of incorporating graphene nanoplatelets (GNPs) in an Ni-based/Zeolite-Y catalyst on the hydrocracking of heptane fuel at two temperatures, 350 and $400{ }^{\circ} \mathrm{C}$. Specifically, reduced GNP/NiO-ZY and NiO-ZY catalysts, each with a $5 \mathrm{wt}$ \% Ni loading, were compared in this study. The results show that the reduced GNP/NiO-ZY enhanced the conversion percentage by $31 \%$ at $350{ }^{\circ} \mathrm{C}$ and by $6 \%$ at $400{ }^{\circ} \mathrm{C}$ as compared with the reduced $\mathrm{NiO}-\mathrm{ZY}$, and the $\mathrm{GNP} / \mathrm{NiO}-\mathrm{ZY}$ also showed superior stability, reporting a less than $2 \%$ drop in conversion over $20 \mathrm{~h}$ of time-on-stream. The enhancement in performance is linked to the surface and texture characteristics of both catalysts. Although the calcined GNP/NiO-ZY possessed a lower Brunauer-Emmett-Teller (BET) surface area of $458 \mathrm{~m}^{2} / \mathrm{g}$ compared with $536 \mathrm{~m}^{2} / \mathrm{g}$ for the calcined NiO-ZY, it showed a more hydrophobic nature, as deduced from the water adsorption profiles, which corroborates the hypothesis that the increased affinity between the catalyst surface and heptane molecules during the reaction leads to an improved catalytic activity.
\end{abstract}

Keywords: hydrocracking; graphene; graphene nanoplatelets; zeolites; catalysis; bi-functional catalyst

\section{Introduction}

In the petrochemical industry, hydrocracking is a major process for refining heavy oils into lighter, added-value chemicals [1] and is carried out in the presence of hydrogen and a catalyst. The catalyst should be able to withstand the harsh reaction conditions, such as a high temperature and pressure, and resist the formation of coke on the catalyst surface. For the aforementioned reasons, the proper selection of the hydrocracking catalyst is crucial for enhancing the performance of the process. While acidity is required for cracking reactions and is often provided by zeolites, metal sites contribute to hydrogenation and dehydrogenation reactions, and thus catalysts for hydrocracking are heterogeneous. Zeolites type-Y are widely used in industrial processes as hydrocracking catalysts because they possess a high stability and activity [2], owing to their high Si/Al ratio which lies in the range of 1.5-3.0 as-synthesized [3], but is remarkably increased upon post-synthetic treatments such as dealumination. For hydrocracking reactions, various metal/support combinations have been reported in the literature and each is associated with different performance characteristics with respect to the conversion percentage, yield, selectivity towards desired products, and coking level as major descriptors. For example, heptane hydrocracking reactions were carried out using an $\mathrm{NiO}-\mathrm{WO}_{3} /$ zeolite-Y bi-functional catalyst [4], where both micro-sized zeolite particles and nano-sized 
zeolites, prepared by ball milling [5,6], were tested for the reaction. The micro-sized zeolites showed a relatively low conversion between 34.6 and $78.3 \mathrm{wt}$. \% at various temperatures, while the nano-sized zeolites exhibited a significantly higher conversion between 95.7 and 98.3 wt. \%. Further, $\mathrm{NiMo} / \mathrm{USY}-\mathrm{Al}_{2} \mathrm{O}_{3}$ was used for hexadecane hydrocracking [7], in which the zeolite recrystallization contributed to the enhancement of the catalyst activity, as expected, due to the higher accessibility of zeolite sites upon recrystallization. Additionally, the Pt/ZSM-22 catalyst was prepared for the hydrocracking n-decane, n-nonadecane, and pristane (2,6,10,14-tetramethylpentadecane), in which its micro-pores resulted in creating mainly linear and cracked fragments [8]. The study concluded that the hierarchical ZSM-22 contributed to reorganizing the distribution of Brønsted acidity, and thus to achieving a superior performance. Bi-functional Pt-loaded MFI zeolite nano-sheets were prepared and tested for the hydrocracking of $n$-decane [9]. The results imply that the production of $C_{5}$ from the hydrocracking was inhibited because of the restricted shape selectivity feature of the MFI-type pores, emphasizing the crucial role that porosity plays in creating or minimizing the diffusion path limitations during the reaction. Thus, it can be concluded that a number of important factors, such as acidity, porosity, and catalyst composition, can all lead to different reaction outcomes and products formed.

In heterogeneous catalysis, a suitable catalyst support is one that has desirable properties, such as a high surface area and porosity, stability under reaction and regeneration conditions, adequate mechanical properties, and appropriate physical form for the type of reactor used [2,10]. From this perspective, carbon-based materials (e.g., carbon nanotubes (CNTs), graphene, graphene-oxide, etc.) have been advocated as leading materials for chemical reactions due to their unique properties. First, they have a large specific surface area (SSA) (although the measured SSAs are typically much lower than the theoretical values: graphene's theoretical SSA is $\sim 2630 \mathrm{~m}^{2} / \mathrm{g}$ while that for discrete single-walled CNTs (SWCNTs) is around $1315 \mathrm{~m}^{2} / \mathrm{g}$ [11]), high porosity, and excellent electron conductivity [12]. Their high porosity facilitates the diffusion of gases and reactants to the active phase through the pores, which in turn improves the dissipation of the reaction heat, minimizing sintering phenomena of the active phase and increasing the poison resistance [13]. They also exhibit a relative chemical inertness while having the ability to be chemically functionalized and decorated with metal nanoparticles to enhance the catalytic activity [14]. With the discovery of graphene and its unique properties, graphene-based catalysts started to gain attention in cracking and hydro-processing reactions. Surface functional groups present in graphene originate from the heteroatoms, such as oxygen, nitrogen, and sulfur, attached to the edges of the graphene layers either naturally or induced upon preparation $[15,16]$. Introducing these heteroatoms affects the electronic properties of the carbon material by providing electron acceptors or donors, which can potentially enhance the $\pi$ bonding, resulting in an improved stability and electron transfer rate, and subsequently, a better performance and durability of the catalyst $[17,18]$.

In this study, we carried out water adsorption studies to examine the hydrophilicity/hydrophobicity nature of the materials used and link this to their performance towards heptane hydrocracking. Although the definition is under debate when it comes to complex systems, generally, a hydrophilic material is one having a high affinity to water [19]. Polar substances such as zeolites and silica gels are classified as hydrophilic, yet some molecular sieves with a neutral framework are described as hydrophilic compounds too [20]. Conversely, hydrophobicity is defined as the low affinity of a sorbent to water [21]. In general, ideal hydrophobic solids rarely exist, since their surfaces will contain hydrophilic sorption sites developed due to defects or accidental impurities [22-24]. Carbon-based compounds are typically hydrophobic in nature, although some of them may exhibit higher water adsorption levels than zeolites and silica gels [25]. The hydrophobicity of Ni-Zeolite-Y with and without GNP is predicted in this study through water adsorption measurements, and since heptane is a hydrophobic compound, a higher affinity with the fuel is desirable as it would enhance the reactivity of the corresponding catalyst.

Furthermore, some studies in the literature reported an enhanced performance in various applications when merging $\mathrm{Ni} / \mathrm{NiO}$ with graphene-like materials, due to their synergistic behavior. 
For instance, $\mathrm{NiO}$ quantum dots/graphene flakes were formed and utilized for supercapacitor applications. $\mathrm{NiO}$ quantum dots were uniformly deposited on few-layer graphene surfaces by the naturally occurring oxygen functional groups on graphene [26]. These functional groups facilitated the bridging of $\mathrm{NiO}$ and graphene through $\mathrm{Ni}-\mathrm{O}-\mathrm{C}$ bonds, leading to an improved electrical conductivity and outstanding specific capacitance. Moreover, Ni/nitrogenated-graphene hybrid electrodes were prepared and their catalytic behavior was analyzed for a hydrogen evolution reaction [27]. The electro-catalytic performance of the $\mathrm{Ni}$ electrodes was significantly improved by the incorporation of nitrogen-functionalized GO flakes in the Ni matrix, changing the reactivity of the materials and suggesting that this composite is more promising than pure electrodeposited $\mathrm{Ni}$ in the long-term use for higher hydrogen production. In addition, the photocatalytic activity of $\mathrm{NiAl}_{2} \mathrm{O}_{4}$ was enhanced by decorating it with graphene quantum dots for water remediation from dyes and toxic pollutants [28]. The outcomes of the study suggested that the hydroxyl radicals played a leading role in this improvement and demonstrated that the synthesized composite exhibited multi-functionality, to be further investigated in future studies. In a different application, an Ni/graphene nanocomposite coating was utilized as an anti-corrosive coating [29]. The composite had a sphere-like morphology and exhibited improved micro-hardness, reduced grain size, and outstanding carrion resistance, caused by the inherent mechanical properties and 2D nano-size of the graphene nano-sheets.

Even though several studies have reported the synthesis of graphene (or graphene oxide)/zeolite composites [30-34], the potential enhancement resulting from the utilization of GNP supported on zeolites for hydrocracking applications, in particular, remains widely unexplored. In this study, we report the synthesis, characterization, and catalytic performance of a GNP/Ni-zeolite-Y composite catalyst for heptane hydrocracking performed at 350 and $400^{\circ} \mathrm{C}$. Although the hydrocracking of heptane is a model reaction, this work aims to examine the extent to which the conversion and selectivity aspects of the hydrocracking reaction are influenced by the presence of GNPs in the conventionally used metal-zeolite Y catalytic system.

\section{Materials and Method}

\subsection{Catalyst Preparation}

Zeolite $\mathrm{Y}$ with the $\mathrm{SiO}_{2} / \mathrm{Al}_{2} \mathrm{O}_{3}$ ratio of 30 was purchased from Zeolyst International $(100 \% w / w)$, whereas graphene nanoplatelets of grade C-300 (quality level, MQ100) were purchased from Sigma Aldrich, and these are referred to as ZY and GNP, respectively, in this manuscript for convenience. For the two catalysts studied in this work, the wet impregnation method was first used to impregnate $\mathrm{Ni}$ on the zeolite $\mathrm{Y}$ support with nickel (II) nitrate hexahydrate, $\mathrm{Ni}\left(\mathrm{NO}_{3}\right)_{2} \cdot 6 \mathrm{H}_{2} \mathrm{O}$, as a precursor. In brief, a calculated amount of $\mathrm{Ni}\left(\mathrm{NO}_{3}\right)_{2} \cdot 6 \mathrm{H}_{2} \mathrm{O}$, corresponding to the targeted $\mathrm{Ni}$ loading, was dissolved in $50 \mathrm{~mL}$ distilled water. The Ni-containing solution was then added to a dispersion of zeolite $\mathrm{Y}$ in $200 \mathrm{~mL}$ distilled water. The obtained mixture was left under magnetic stirring and at mild heating of $50{ }^{\circ} \mathrm{C}$ until the water evaporated. The amounts of the Ni precursor and zeolite were determined such to achieve $5 \mathrm{wt}$. \% Ni on the zeolite. After the wet impregnation, the catalysts were dried for $12 \mathrm{~h}$ at $120^{\circ} \mathrm{C}$ and then cooled to room temperature. Finally, both catalysts were calcined in air at $500{ }^{\circ} \mathrm{C}$ for $5 \mathrm{~h}$ to obtain NiO-ZY.

$\mathrm{Ni}-\mathrm{ZY}$ catalysts synthesis: NiO-ZY obtained after calcination was reduced in $\mathrm{H}_{2}$ at $550{ }^{\circ} \mathrm{C}$ for $3 \mathrm{~h}$ in situ preceding the catalytic testing, in order to obtain Ni nanoparticles on the zeolite, Ni-ZY.

GNP/Ni-ZY synthesis: The preparation method is similar to that explained in [34]. Briefly, GNP was dissolved in ethanol and allowed to sonicate for $1 \mathrm{~h}$. NiO-ZY, as received after calcination, was added to the GNP solution in the ratio of GNP/NiO-ZY of 1:15 and further sonicated for $3 \mathrm{~h}$. The solution was then centrifuged at $6500 \mathrm{rpm}$ for $10 \mathrm{~min}$ and the collected powder was finally dried in the oven, obtaining GNP/NiO-ZY. Similarly, the catalyst was reduced in situ prior to the catalytic testing in $\mathrm{H}_{2}$ at $350{ }^{\circ} \mathrm{C}$ for $3 \mathrm{~h}$. The reduced catalyst is named GNP/Ni-ZY in this manuscript. It is worth noting here that because the catalyst reduction was done in situ for both materials, the characterization was done 
earlier for the calcined NiO-ZY and GNP/NiO-ZY, while the catalytic results are rather reported for the reduced catalysts, namely Ni-ZY and GNP/Ni-ZY. Although more coherent information could have been provided by characterizing the reduced catalysts, the main focus of this study is to examine the effect of incorporating GNPs into the catalysts rather than the extent of the reduction of $\mathrm{NiO}$ into $\mathrm{Ni}$. Recent reports on Ni-based catalysts with similar Ni loadings show that an Ni reduction can lead to the reduction of $\mathrm{Ni}^{2+}$ to $\mathrm{Ni}$ to a variable extent, depending on the support [35,36]. The reduction temperature in this study was chosen such to ensure the thermal stability of the carbon-loaded catalyst in agreement with the literature [37-40].

\subsection{Catalyst Characterization}

Several analytical techniques were used to characterize the fresh catalysts for investigating their bulk and surface properties. The following sub-sections briefly describe the employed techniques.

\subsubsection{BET Surface Area}

The total specific surface areas and porosities of the catalysts were measured by $\mathrm{N}_{2}$ adsorptiondesorption at $77 \mathrm{~K}$ using a 3Flex Physisorption porosimeter (Micrometrics, Atlanta, GA, USA). The surface areas and the micropore volume measurements were determined by applying the Brunauer-Emmett-Teller (BET) method [41,42] and t-plots, respectively. The pore size distribution of the catalysts was acquired using the Barrett, Joyner, and Halenda (BJH) method [43]. Degassing under a vacuum at $120^{\circ} \mathrm{C}$ was carried out for $5 \mathrm{~h}$ before the adsorption-desorption measurements to remove any previously desorbed gases in the pores of the catalyst.

\subsubsection{Water Adsorption}

The water adsorption results were collected using a 3Flex Physisorption porosimeter (Micrometrics, Atlanta, GA, USA) with water adsorption accessories attached. The accessories include a water vapor source and a temperature-controlled analysis manifold. The water vapor was generated at a constant temperature of $42^{\circ} \mathrm{C}$, whereas the $\mathrm{H}_{2} \mathrm{O}$ adsorption study was carried out at $30^{\circ} \mathrm{C}$.

\subsubsection{X-ray Diffraction}

The crystalline structure of the fresh catalysts was studied by the X-ray diffraction (XRD) analysis using the Bruker D2 Phaser XRD (Billerica, MA, USA) with a radiation wavelength of $1.54184 \AA$ $(\mathrm{Cu}-\mathrm{K} \alpha)$ at $30 \mathrm{kV}$ and $10 \mathrm{~mA}$ between $2 \theta$ angles of $5^{\circ}$ and $50^{\circ}$. In addition, the crystallite size, $\mathrm{D}$, was determined using the Scherrer equation $[44,45]$ for $\mathrm{NiO}$ crystals:

$$
D=(K \times \lambda) /(\mathrm{FWHM} \times \cos \theta),
$$

where $D$ is the crystallite size, $K$ is a dimensionless shape factor, $\lambda$ is the $X$-ray wavelength, FWHM is the full-width (line broadening) at the half maximum of the peak, and $\theta$ is the Bragg angle.

\subsubsection{Raman Spectroscopy}

Raman spectroscopy was carried out on a Raman-AFM combination Witec Alpha300 RA (Ulm, Germany) for both catalysts using a laser wavelength of $532 \mathrm{~nm}$, from which the characteristics of the graphene nanoplateletes (GNPs) were examined.

\subsubsection{Scanning/Transmission Electron Microscopy Imaging (SEM/TEM)}

The high-resolution scanning electron microscopy (HR-SEM) and the transmission electron microscopy (TEM) were used to observe the morphology of the catalysts. The HR-SEM imaging was performed using an FEI Nova NanoSEM 650 (Hillsboro, OR, USA), whereas the TEM imaging was done on an FEI Tecnai (Hillsboro, OR, USA) with a line resolution of $0.20 \mathrm{~nm}$. An elemental analysis was carried out, too, using energy dispersive X-ray spectroscopy (EDX). A silicon drift detector 
(SDD) for the EDX mounted on a scanning electron microscope was utilized to analyse the specimen's elemental chemistry.

\subsubsection{Temperature-Programmed Desorption (TPD)}

The temperature-programmed desorption of ammonia TPD- $\mathrm{NH}_{3}$ was done in a chemisorption AutoChem II 2920 unit (Micrometrics, Atlanta, GA, USA) for the catalysts to evaluate their acid properties. The steps involved in TPD- $\mathrm{NH}_{3}$ were as follows: $20 \% \mathrm{O}_{2}$ in $\mathrm{He}$ was passed while ramping the temperature to $400{ }^{\circ} \mathrm{C}$ at a rate of $30^{\circ} \mathrm{C} / \mathrm{min}$; the gas was then switched to He for $10 \mathrm{~min}$, then the temperature was reduced to $30{ }^{\circ} \mathrm{C}$ at a rate of $30{ }^{\circ} \mathrm{C} / \mathrm{min} ; 2 \% \mathrm{NH}_{3}$ in He was then passed and kept flowing for $1 \mathrm{~h}$ (adsorption); He was allowed to flow for $15 \mathrm{~min}$, then recording started while raising the temperature to $600{ }^{\circ} \mathrm{C}$ at a rate of $10^{\circ} \mathrm{C} / \mathrm{min}$ (desorption).

\subsection{Catalytic Testing}

The heptane hydrocracking experiments were carried out in an Autoclave Engineers BTRS (Erie, PA, USA) high-temperature and high-pressure testing system, equipped with a high-pressure HPLC pump (Series I) and metering valves to control the flow rate of the liquid and gas feed, respectively.

Procedure: A continuous flow, fixed bed tubular stainless-steel reactor was used in the experiments with an internal diameter of $0.7 \mathrm{~cm}$, length of $30 \mathrm{~cm}$, and volume of $12 \mathrm{~mL}$. The reduction in $100 v / v \%$ of $\mathrm{H}_{2}(50 \mathrm{~mL} / \mathrm{min})$ in atmospheric pressure was carried out in situ prior to the catalytic testing. For NiO-ZY, the latter reduction was carried out at $550{ }^{\circ} \mathrm{C}$, while for the GNP/NiO-ZY, a lower temperature of $350{ }^{\circ} \mathrm{C}$ was used due to the fact that GNP starts to degrade thermally between $400-500{ }^{\circ} \mathrm{C}$, according to previous studies [37-40]. Next, the system was set to the desired reaction temperature under a flow of high-purity $\mathrm{N}_{2}(100 \mathrm{~mL} / \mathrm{min})$ and pressurized with $\mathrm{H}_{2}$ at 5 bar. Heptane $>99 \%$ solution was introduced to the system at a rate of $0.035 \mathrm{~mL} / \mathrm{min}$, along with a flow of $\mathrm{H}_{2}$. Liquid and gaseous products were passed through a liquid-gas separator, placed downstream from the catalyst bed; liquid products were manually collected for analysis (gas chromatographer (GC)/mass spectrometer (MS)), while the gas stream was sent to the GC.

The heptane hydrocracking experiments were conducted using two different reaction temperatures, 350 and $400{ }^{\circ} \mathrm{C}, \mathrm{H}_{2}$ pressure of 5 bar, liquid hourly space velocity (LHSV) of $4.2 \mathrm{~h}^{-1}$, and $\mathrm{H}_{2} /$ heptane ratio of 3:1. Each test was performed for $3 \mathrm{~h}$ using a fresh catalyst, and the liquid products were analyzed at $1 \mathrm{~h}$ intervals. Additionally, stability tests were carried out for $20 \mathrm{~h}$ for each catalyst.

Product analysis: The liquid samples were analyzed on an Agilent 7890A/5975C Triple-Axis Detector diffusion pump gas chromatographer-mass spectrometer (GC-MS) equipped with an Agilent Multimode inlet. High injection and column temperatures were used to directly analyze the $n$-Alkanes so as to avoid chemical derivatization. The split/split-less injector was operated in the split mode with a split ratio of $25: 1$ and a split flow of $50 \mathrm{~mL} / \mathrm{min}$ using a deactivated open-ended helix liner (Agilent Technologies, Santa Clara, CA, USA). The temperature of the inlet was $300{ }^{\circ} \mathrm{C}$ for the duration of the analysis and the volume of the samples injected was $1 \mu \mathrm{L}$. The oven temperature program was initially set at $30{ }^{\circ} \mathrm{C}$ for $8 \mathrm{~min}$ and then it was increased by $8{ }^{\circ} \mathrm{C} / \mathrm{min}$ to $250{ }^{\circ} \mathrm{C}$. The maximum temperature was maintained for $5 \mathrm{~min}$ and the total run time was $40 \mathrm{~min}$. An Agilent $30 \mathrm{~m} \times 320 \mu \mathrm{m} \times 0.1 \mu \mathrm{m}$ J\&W DB5-HT capillary column (5\% phenyl, 95\% methylpolysiloxane) was employed to achieve the chromatographic separation, operated under a constant flow rate mode of He $(2 \mathrm{~mL} / \mathrm{min})$. The temperature of the ion source, the quadrupole, and the MS interface for both instruments were 230, 150, and $330^{\circ} \mathrm{C}$, respectively. The GC/MSD Chemstation software was used to obtain the chromatographic data. The gaseous reaction products were analyzed on-line by gas chromatography in a GC-Agilent 7890A gas chromatographer with two columns in parallel, HP Plot-Q (19095-Q04, 30 m length, 0.530 mm I.D.), and HP-Molesieve (19095P-MSO, 30 m length, 0.530 mm I.D.), equipped with thermal conductivity detector (TCD) and flame ionization detector (FID). 
Reaction metrics: The total conversion percentage was calculated as

$$
\% \text { Total conversion }=\left(X_{\mathrm{i}}-X_{\mathrm{f}}\right) / X_{\mathrm{i}} \times 100 \text {, }
$$

where $X_{\mathrm{i}}$ is the initial heptane (feed) mass and $X_{\mathrm{f}}$ is the final heptane mass.

The selectivity percentage of each product, $i$ was calculated according to

$\%$ Selectivity of $i=(\mathrm{C}$ atoms in species $i / \mathrm{C}$ atoms produced in the products $) \times 100$,

where species $i$ refers to ethylene, ethane, methane, propane, iso-Butane, $n$-Butane, and $n$-hexane.

\section{Results and Discussion}

\subsection{Textural Studies}

The $\mathrm{N}_{2}$ adsorption-desorption study at $77 \mathrm{~K}$ was carried out for the two catalysts NiO-ZY and GNP/NiO-ZY, and ZY as a reference. Table 1 presents the textural properties of the materials including the BET surface areas, pore volumes, and average pore diameters during adsorption and desorption. It can be deduced that, upon the wet impregnation followed by calcination, the BET surface area of the metal-supported catalyst decreases from 559 to $536 \mathrm{~m}^{2} / \mathrm{g}$, since the Ni particles deposit on the micropores of the zeolite, causing a slight pore blockage [46]. This effect is also supported by the simultaneous decrease in micropore volume from 0.23 to $0.2 \mathrm{~cm}^{3} / \mathrm{g}$. On the other hand, the average pore diameters increased as a result of the pores' widening upon calcination. GNP/NiO-ZY revealed a decrease in the BET surface area from 536 to $458 \mathrm{~m}^{2} / \mathrm{g}$, caused by the inclusion of GNPs that have a lower BET surface area of $300 \mathrm{~m}^{2} / \mathrm{g}$, as reported by the suppliers. GNPs consist of aggregates of platelets having a particle diameter of less than $2 \mu \mathrm{m}$ and macropores, a reason for which GNP/NiO-ZY shows a significantly higher average pore diameter as compared with the other materials.

Table 1. Textural properties of the prepared catalysts and the as-received zeolite Y.

\begin{tabular}{ccccccc}
\hline & $\begin{array}{c}\text { BET Surface } \\
\text { Area }\left(\mathbf{m}^{2} / \mathbf{g}\right)\end{array}$ & \multicolumn{2}{c}{ More Volume $\left(\mathbf{c m}^{\mathbf{3}} \mathbf{g}\right)$} & \multicolumn{2}{c}{ Average Pore Diameter (nm) } \\
Micropore & Mesopore & Total & Adsorption & Desorption \\
\hline GNP & 300 & - & - & - & - & - \\
ZY & 559 & 0.23 & 0.14 & 0.37 & 2.67 & 2.68 \\
NiO-ZY & 536 & 0.20 & 0.18 & 0.38 & 2.86 & 2.87 \\
GNP/NiO-ZY & 458 & 0.17 & 0.19 & 0.36 & 3.11 & 3.14 \\
\hline
\end{tabular}

Figure 1 presents the $\mathrm{N}_{2}$ adsorption-desorption isotherms and $\mathrm{BJH}$ pore size distribution for the three materials. According to the IUPAC classification, the isotherms are all type IV, indicating mesoporous materials, and have a hysteresis loop of type $\mathrm{H} 3$ attributed to the presence of slit-shaped pores. It also observed a steep slope during desorption at $\mathrm{P} / \mathrm{P}_{\mathrm{o}}$ of around 0.45 , which is related to the tensile strength effect phenomenon arising for $\mathrm{N}_{2}$ at $77 \mathrm{~K}$ at this relative pressure range [47]. While the isotherms showed similar trends for the three materials, a lower $\mathrm{N}_{2}$ adsorption level was reported for GNP/NiO-ZY as compared with $\mathrm{NiO}-\mathrm{ZY}$ and $\mathrm{ZY}$, which is consistent with their corresponding surface areas and pore structures explained earlier. 

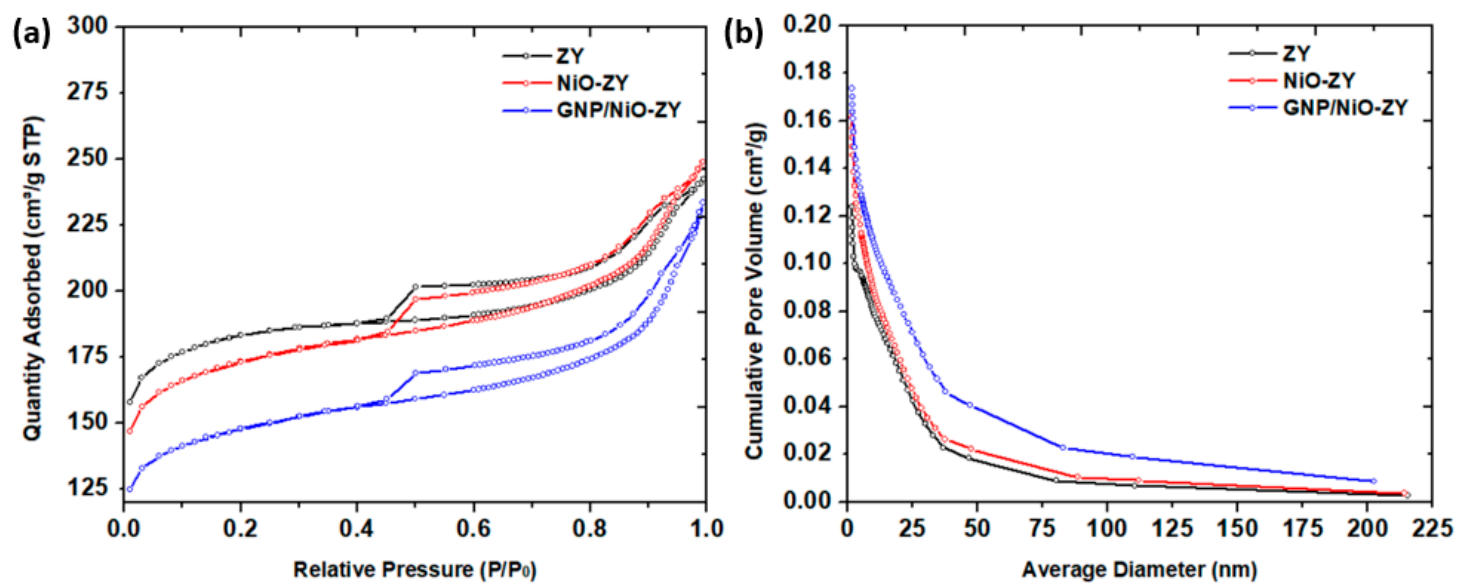

Figure 1. (a) $\mathrm{N}_{2}$ adsorption-desorption isotherms and (b) Barrett, Joyner, and Halenda (BJH) pore size distribution for ZY, NiO-ZY, and GNP/NiO-ZY.

\subsection{Water Adsorption Studies}

The water adsorption isotherms for GNP/NiO-ZY and NiO-ZY carried out at $30{ }^{\circ} \mathrm{C}$ are shown in Figure 2. Both isotherms generally resemble type IV, according to IUPAC, indicating a hydrophilic material with some hydrophobic sorption sites [48]. Although zeolites are mainly considered highly hydrophilic, producing a type I isotherm, the hydrophobicity in zeolites can originate from the weak interaction of water molecules with the non-polar $\equiv \mathrm{Si}-\mathrm{O}-\mathrm{Si} \equiv$ bonding as well as from the absence of partially ionic hydrophilic centers related to tetrahedrally coordinated aluminum in high $\mathrm{SiO}_{2} / \mathrm{Al}_{2} \mathrm{O}_{3}$ ratio zeolites [49]. The results indicate that the $\mathrm{GNP} / \mathrm{NiO}-\mathrm{ZY}$ catalyst has a lower water adsorption capacity across the pressure range considered, as compared with NiO-ZY. The water uptake at $30{ }^{\circ} \mathrm{C}$ and $\mathrm{P} / \mathrm{P}_{\mathrm{o}}$ of 0.75 are 9.7 and $12.3 \mathrm{mmol} / \mathrm{g}(0.18$ and $0.22 \mathrm{~g} / \mathrm{g})$ for $\mathrm{GNP} / \mathrm{NiO}-\mathrm{ZY}$ and $\mathrm{NiO}-\mathrm{ZY}$, respectively. The water adsorption capacity of zeolites, as reported in the literature, ranges between 0.2 to $0.45 \mathrm{~g} / \mathrm{g}$ [19], in which NiO-ZY without GNP lies. Variations in the water uptake level often result from differences in pore size, pore volume, and the nature of the pores in the material [50]. The capacity of water adsorption is enhanced with an enlarging the pore volume and is seen to be proportional to the pore size of the material [19]. These findings are consistent with the results in this study, where NiO-ZY, having a pore volume of $0.38 \mathrm{~cm}^{3} / \mathrm{g}$, showed higher water adsorption than GNP/NiO-ZY, with a pore volume of $0.36 \mathrm{~cm}^{3} / \mathrm{g}$. Furthermore, the adsorption rate of the latter catalyst is slower and this can be deduced from its lower isotherm slope, especially at a low $\mathrm{P} / \mathrm{P}_{\mathrm{o}}$ ratio $(<0.3)[30]$, indicating that $\mathrm{GNP} / \mathrm{NiO}-\mathrm{ZY}$ has more hydrophobic adsorption sites than $\mathrm{NiO}-\mathrm{ZY}$ due to the presence of the highly hydrophobic GNP in the catalyst [51,52]. This property of the composite catalyst shall assist in the enhancement of heptane/heptane originating fragments' sticking efficiency on the catalyst surface, which is anticipated to lead to a higher hydrocracking activity since heptane is hydrophobic in nature, and the presence of hydrophobic sites on the catalyst will improve the affinity between the catalyst and heptane, which is expected to increase the conversion rate. This will be further discussed in Section 3.5. 


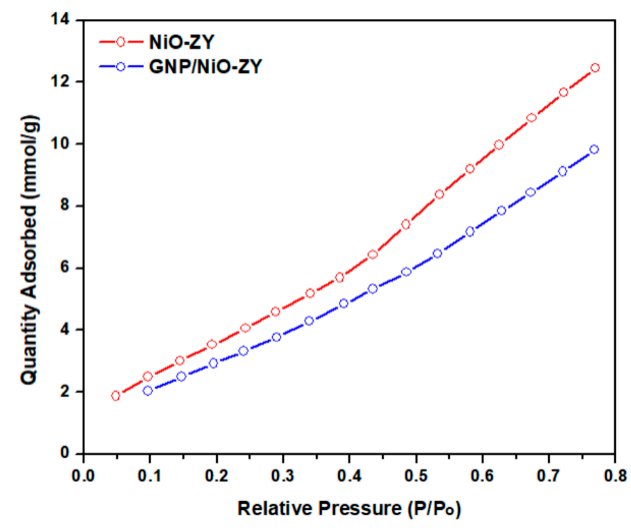

Figure 2. $\mathrm{H}_{2} \mathrm{O}$ adsorption isotherms at $30{ }^{\circ} \mathrm{C}$ for NiO-ZY and $\mathrm{GNP} / \mathrm{NiO}-\mathrm{ZY}$.

\subsection{Structural and Morphological Studies}

Figure 3a presents the XRD diffractograms in the $5^{\circ}-50^{\circ} 2 \theta$ range for GNP/NiO-ZY, NiO-ZY, and the neat GNP. The cubic structure of $\mathrm{NiO}$ is indicated by the main diffraction peaks indexed as (111) at $2 \theta$ of $37.3^{\circ},(200)$ at $43.3^{\circ}$, and (220) at $62.9^{\circ}$ crystal planes, while the Ni peaks are indexed as (111) at $2 \theta$ of $44.5^{\circ},(200)$ at $51.9^{\circ}$, and (220) at $76.4^{\circ}$ [53]. The crystallite size, D, has been calculated using the Scherrer equation (Equation (1)), considering a shape factor of $K=0.9$ at the (200) plane of $\mathrm{NiO}$ for both catalysts, and the results are shown in Table 2. It can be deduced that the crystallite size of $\mathrm{NiO}$ in GNP/NiO-ZY, $7.8 \mathrm{~nm}$, was smaller than that in NiO-ZY, $9.5 \mathrm{~nm}$, indicating that in the presence of GNP, a recrystallization of $\mathrm{NiO}$ took place, achieving a better dispersion of the $\mathrm{NiO}$ crystals.

Table 2. Crystallite size calculated from XRD pattern using the Scherrer equation.

\begin{tabular}{cc}
\hline Catalyst Composition & Crystallite Size, $\boldsymbol{D}_{\mathrm{NiO}}(\mathbf{n m})$ \\
\hline $\mathrm{NiO}-\mathrm{ZY}$ & 9.5 \\
$\mathrm{GNP} / \mathrm{NiO}-\mathrm{ZY}$ & 7.8 \\
\hline
\end{tabular}
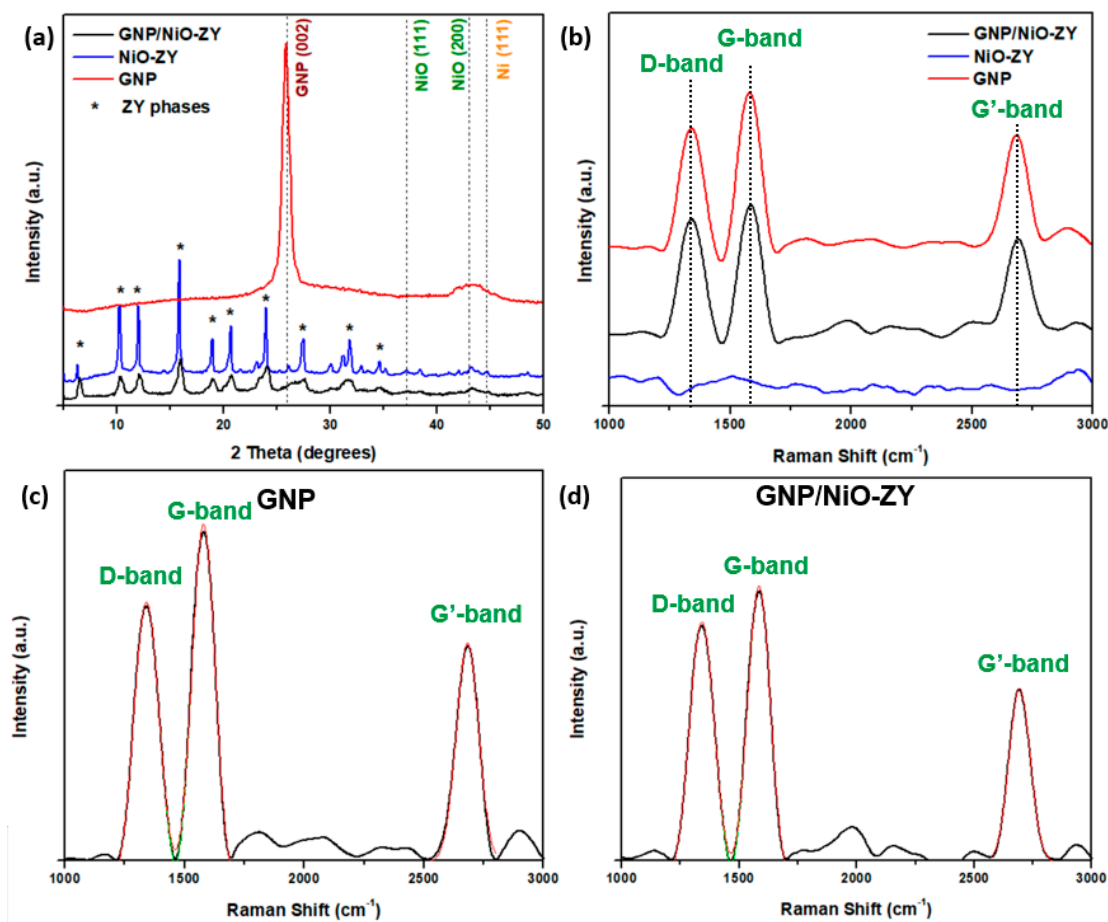

Figure 3. (a) XRD patterns and (b) Raman shifts of GNP/NiO-ZY, NiO-ZY, and graphene nanoplatelet (GNP), as well as spectral fitting curves of (c) GNP and (d) GNP/NiO-ZY. 
Although the high crystallinity of zeolites hides other peaks, small diffraction peaks are shown at $43.3^{\circ}$ and $44.5^{\circ}$, indicating the presence of $\mathrm{NiO}$ and $\mathrm{Ni}$ particles, respectively. The GNP diffractogram shows a major peak at $2 \theta$ of $26^{\circ}$, similar to the peak reported in literature for GNP [54], which was barely observed in the composite catalyst due to the small amount of GNP as compared with zeolite Y. It is also evident that the crystallinity of GNP/NiO-ZY slightly dropped as compared with $\mathrm{NiO}-\mathrm{ZY}$, and this is caused by the prolonged sonication treatment during the material preparation, as ultrasonic irradiation may lead to the fragmentation of existing crystals following crystal collisions [55].

Moreover, Figure $3 b$ shows the Raman shifts of GNP/NiO-ZY, NiO-ZY, and GNP. GNPs have a pristine graphitic surface of $\mathrm{sp}^{2}$ carbon molecules that makes them especially suitable for applications demanding a high electrical or thermal conductivity. The presence of GNP is characterized by three main peaks, as shown in Figure 3b, indicating the G-band, D-band, and G' band at around 1580, 1338, and $2682 \mathrm{~cm}^{-1}$, respectively, comparable to the values reported in the literature for GNP [56]. While the $\mathrm{G}$-band is associated with the existence of a crystalline graphitic carbon made of $\mathrm{sp}^{2}$-bonded carbon, the D-band rather indicates lattice distortions and a defective carbon [57]. The $\mathrm{I}_{\mathrm{D}} / \mathrm{I}_{\mathrm{G}}$ ratio, relative to the intensities of the $\mathrm{D}$ and $\mathrm{G}$ bands, is around 0.67 for GNP/NiO-ZY, and 0.6 for GNP, showing a slight increase in defects of the carbon structure upon catalyst preparation. A numerical fitting of the Raman spectra was carried out to further analyze the bands in GNP and GNP/NiO-ZY, which resembled the Gaussian character and are given in Figure 3c,d. Table 3 shows the peak frequencies and their corresponding areas for the $D, G$, and $G^{\prime}$ bands. These areas correspond to the population of graphitic and defective carbons, which were both less for GNP/NiO-ZY. Besides, all bands revealed a substantial broadening, often portrayed as a disorder in the structure and/or strong surface modification [58].

Table 3. Peak frequencies and areas of the various Raman bands for GNP and GNP/NiO-ZY.

\begin{tabular}{|c|c|c|c|c|}
\hline \multirow[b]{2}{*}{ Peak } & \multicolumn{2}{|l|}{ GNP } & \multicolumn{2}{|c|}{ GNP/NiO-ZY } \\
\hline & Raman Shift $\left(\mathrm{cm}^{-1}\right)$ & Area & Raman Shift $\left(\mathrm{cm}^{-1}\right)$ & Area \\
\hline D-band & 1340.6 & 1478.5 & 1341.3 & 1333.1 \\
\hline G-band & 1579.0 & 1723.0 & 1583.6 & 1618.1 \\
\hline $\mathrm{G}^{\prime}$-band & 2681.5 & 980.4 & 2693.0 & 770.8 \\
\hline
\end{tabular}

Figure 4 presents the high-resolution scanning electron microscopy (HR-SEM) images for (a) GNP/NiO-ZY, (b) GNP without sonication, and (c) NiO-ZY, as well as the transmission electron microscopy (TEM) image for (d) GNP/NiO-ZY, showing a higher magnification morphology of each of GNP, ZY, and $\mathrm{NiO}$ in the composite catalyst. Figure 4e shows the elemental analysis done on SEM-EDX for GNP/NiO-ZY, obtained after an area scanning, where the percentages by weight for the existing elements are as follows: 14 wt. \% C, 2 wt. \% Al, 37 wt. \% Si, and 4 wt. \% Ni. GNPs are unique nanoparticles made up of short stacks of graphene sheets with a platelet shape, as shown in Figure 4a,b. The HR-SEM images show that zeolite particles impregnated with NiO surround the GNP particles, which in turn have naturally occurring functional groups like ethers, carboxyls, or hydroxyls attached on their edges, as reported by the GNP suppliers. 

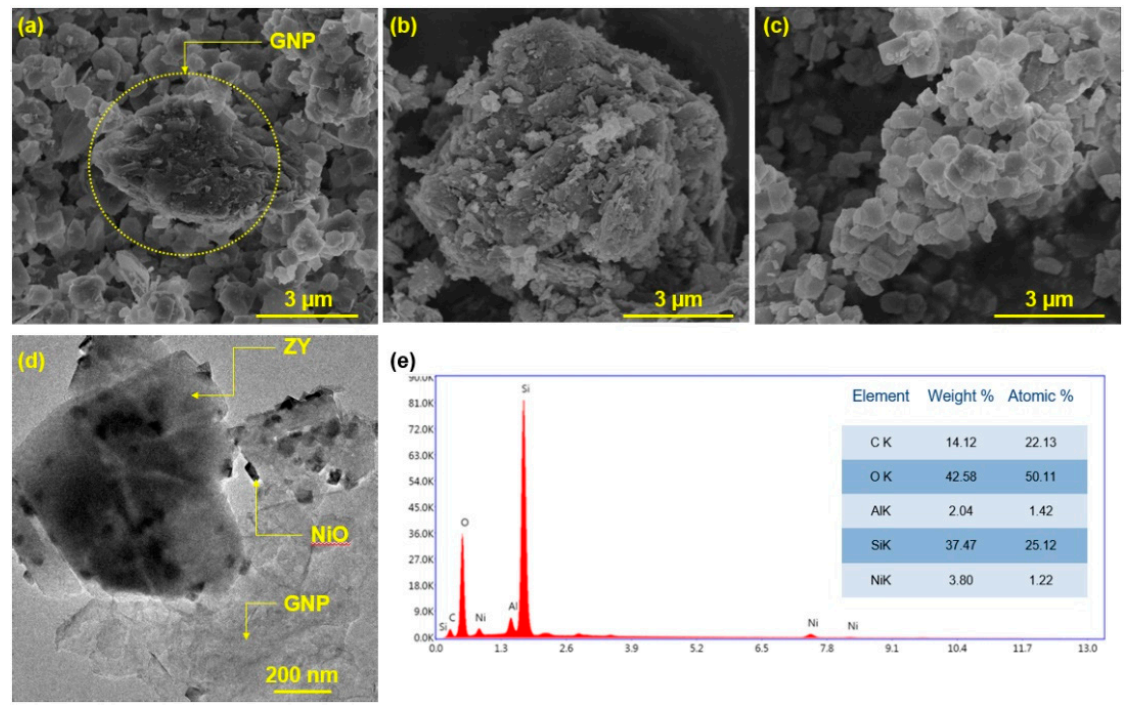

Figure 4. SEM images of (a) GNP/NiO-ZY, (b) GNP, and (c) NiO-ZY, TEM image of (d) GNP/NiO-ZY, and (e) EDX analysis of GNP/NiO-ZY.

\subsection{Surface Acidity}

Figure 5 shows the TPD-NH $\mathrm{N}_{3}$ profiles obtained over NiO-ZY and GNP/NiO-ZY for a temperature rising from 30 to $600{ }^{\circ} \mathrm{C}$. The $\mathrm{NH}_{3}$ desorption peaks are often classified according to the temperature range in which they occur: weak acid sites in the low-temperature region of $100-300^{\circ} \mathrm{C}$, medium/strong acid sites in the higher temperature region of $300-600{ }^{\circ} \mathrm{C}[59,60]$, and peaks above $600{ }^{\circ} \mathrm{C}$. Above $600{ }^{\circ} \mathrm{C}$, peaks may originate from the $\mathrm{N}_{2}$ and $\mathrm{NO}_{x}$ formation from the adsorbed $\mathrm{NH}_{3}$ on the catalyst's surface [61], and therefore TPD was obtained for a temperature up to $600{ }^{\circ} \mathrm{C}$ in this study. From the aforementioned classifications, weak acid sites are dominant in both catalysts as indicated by the high-intensity peaks, with slightly more weak sites in the GNP/NiO-ZY catalyst. The major peaks around $100{ }^{\circ} \mathrm{C}$ are in accordance with the TPD-NH 3 profiles for the protonated Ni-ZY studies in the literature [62]. Small intensity peaks are present in the medium/strong acid sites region at different temperatures for each catalyst, in which the intensity of the TCD signal is higher for the $\mathrm{NiO} / \mathrm{ZY}$ catalyst.

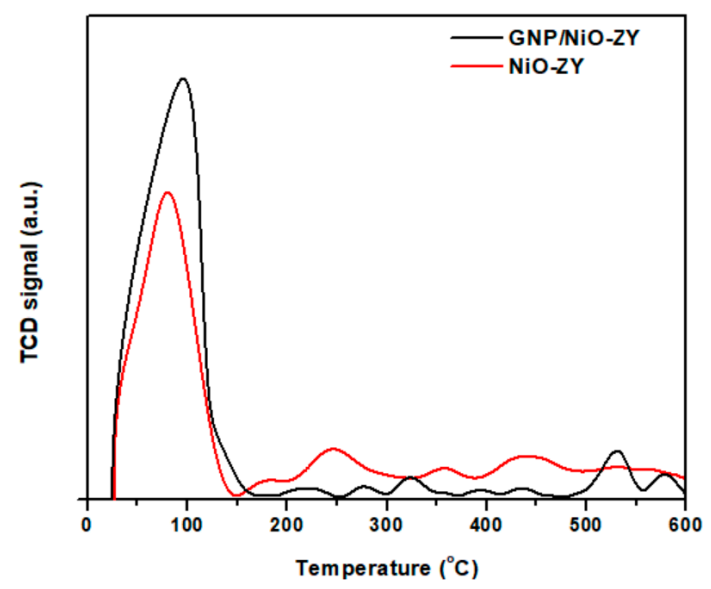

Figure 5. $\mathrm{TPD}-\mathrm{NH}_{3}$ profiles of $\mathrm{GNP} / \mathrm{NiO}-\mathrm{ZY}$ and $\mathrm{NiO}-\mathrm{ZY}$.

\subsection{Catalytic Performance}

Figure 6a shows the conversion percentages of heptane for both catalysts at the two tested temperatures of 350 and $400^{\circ} \mathrm{C}$. The reported conversion values at $350^{\circ} \mathrm{C}$ were $81.6 \%$ and $62.3 \%$, whereas 
at $400{ }^{\circ} \mathrm{C}$, they were $83.3 \%$ and $78.3 \%$, for GNP/Ni-ZY and Ni-ZY, respectively. Thus, GNP/Ni-ZY exhibits a conversion percentage higher than Ni-ZY by $31 \%$ at $350{ }^{\circ} \mathrm{C}$ and by $6 \%$ at $400{ }^{\circ} \mathrm{C}$ (the conversion percentage is calculated as the difference in conversion of both catalysts over the conversion of Ni-ZY). The effect of the temperature rise from 350 to $400{ }^{\circ} \mathrm{C}$ clearly enhanced the performance of both catalysts, but the effect was more pronounced for the Ni-ZY. Interestingly, GNP/Ni-ZY had a superior performance at the lower temperature, $350^{\circ} \mathrm{C}$, as compared with its counterpart, suggesting that the inclusion of GNPs could improve the reaction performance particularly at low temperatures. This has an important practical significance as it supports the fact that active catalysts can be designed to operate at lower temperatures, making the temperature increase unnecessary. In addition, Figure $6 \mathrm{~b}$ presents the stability results for $20 \mathrm{~h}$ of time-on-stream at $400{ }^{\circ} \mathrm{C}$, where GNP/Ni-ZY demonstrates an outstanding catalytic stability with time, reporting a conversion drop of less than $2 \%$, significantly lower than the $14 \%$ drop in conversion observed for the Ni-ZY catalyst. The findings of the catalytic study can be correlated to the characterization results in a number of ways. Although the BET surface area of GNP/Ni-ZY was lower than that of Ni-ZY (see Table 1), the former composite catalyst was more catalytically active, due to its higher hydrophobicity as predicted by the water adsorption study (see Figure 2). The increased population of hydrophobic sites improves the affinity between the catalyst and the hydrophobic heptane (solubility in water $0.0003 \%$ at $25^{\circ} \mathrm{C}$ ) [63] molecule, allowing for increased contact, and thus leading to a higher hydrocracking efficiency. It has to be mentioned here that the authors are aware of the fact that the reaction temperature was at $350{ }^{\circ} \mathrm{C}$, whereas the water adsorption isotherms were acquired at near ambient conditions. The catalysts, though, were calcined at $350{ }^{\circ} \mathrm{C}$, before the water adsorption experiment. This experiment aims to shed some light on the static hydrophobic/hydrophilic sites and not their evolution under the reaction conditions. The XRD results portray a reduction in the NiO crystal size upon the inclusion of GNP to the catalyst, which sequentially indicates a better dispersion of the $\mathrm{NiO}$ crystals, leading to a higher catalytic activity as the active sites are better exposed. The unique properties of GNPs, such as their high thermal conductivity contributed, in turn, to the improved performance of the composite catalyst during this reaction. The high thermal conductivity of the catalyst not only allows it to withstand the reaction temperature and maintain stability for a longer time, but also facilitates the reaction of heat dissipation, reducing the possibility of active phase sintering phenomena. The acidity characterizations, as deduced from the TPD-NH $\mathrm{H}_{3}$ profiles (see Figure 5), showed that GNP/NiO-ZY had more acid sites in the low temperature regions, but not in the medium/strong acid sites region, which does not seem to be the main contributor to the enhanced catalytic activity.
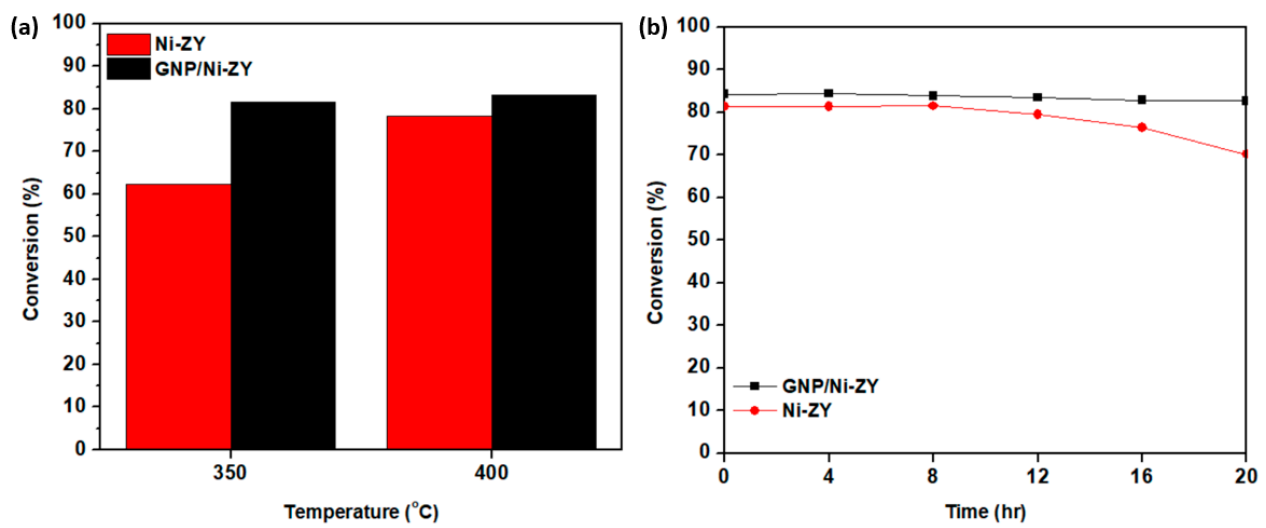

Figure 6. Conversion levels over Ni-ZY and GNP/Ni-ZY (a) at 350 and $400{ }^{\circ} \mathrm{C}$ reaction temperatures, (b) with stability results for $20 \mathrm{~h}$ of time-on-stream at $400{ }^{\circ} \mathrm{C}$.

Figure 7 shows the selectivity percentages towards the hydrocarbon products over (a) Ni-ZY and (b) GNP/Ni-ZY at both temperatures, as well as (c) both catalysts' selectivity results compared at $400{ }^{\circ} \mathrm{C}$. By varying the reaction temperature, the product selectivity percentages remain almost unchanged 
for both catalysts, however, remarkable differences can be pointed out when comparing the catalysts to each other at a certain temperature. For instance, the selectivity towards propane is much higher (and is the dominant product) over GNP/Ni-ZY, as compared with Ni-ZY, which yields iso-butane more than the other hydrocarbons. Moreover, it is evident that the selectivity towards n-hexane is much larger in Ni-ZY, and thus it can be deduced that n-hexane cracks further into propane with GNP/Ni-ZY, which is less pronounced with Ni-ZY. Additionally, for GNP/Ni-ZY, there is more ethylene and less ethane, which indicates that the hydrogenation of ethylene to ethane over the metal nanoparticles is not as effective for GNP/Ni-ZY as compared with Ni-ZY. Knowing that the hydrocracking process involves the breakdown of large fuels into smaller ones, it is definitely of interest to produce more of the lighter molecules for a greater catalytic performance. This further proves that GNP/Ni-ZY achieved a better performance in the heptane hydrocracking under the tested reaction conditions.
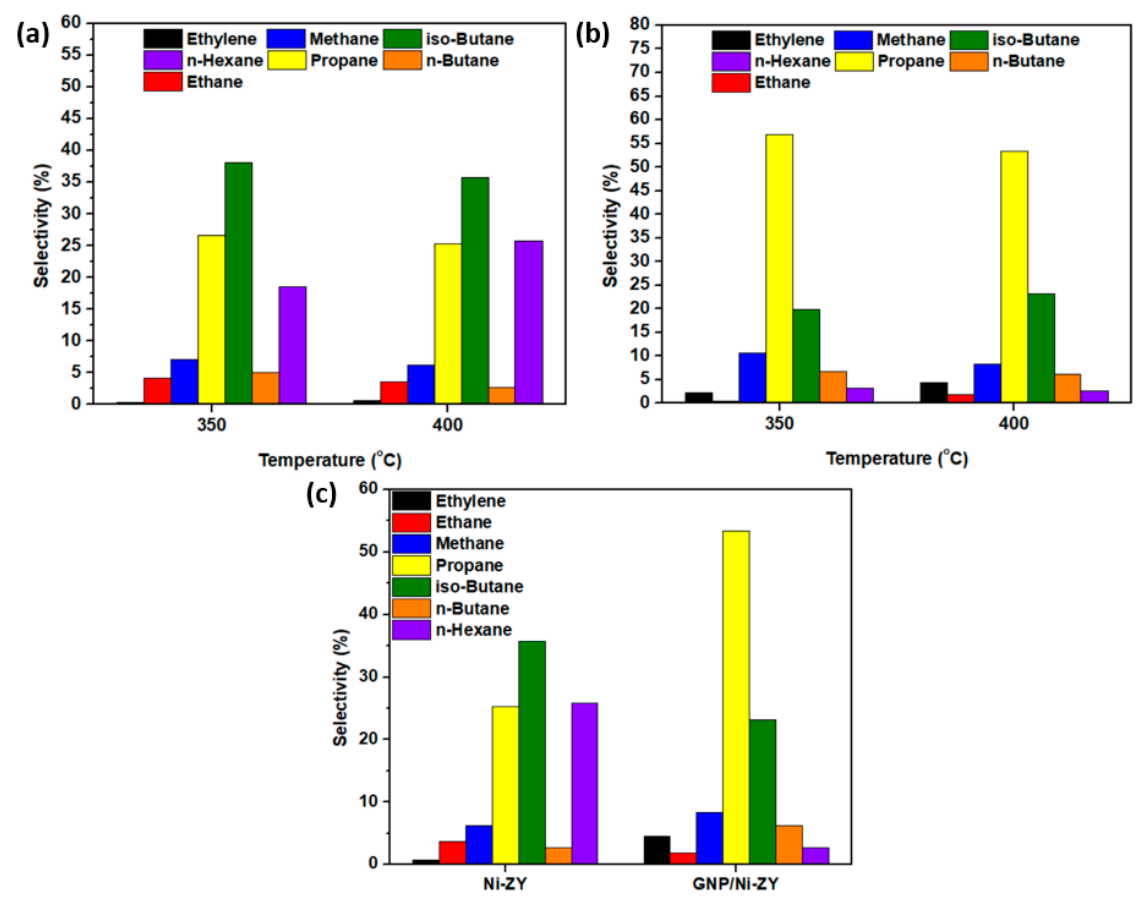

Figure 7. Selectivity towards various products over (a) Ni-ZY and (b) GNP/Ni-ZY as well as (c) both selectivities compared at $400^{\circ} \mathrm{C}$.

\section{Conclusions}

In this study, we report the synthesis and characterization of a calcined GNP/NiO-ZY composite catalyst and the catalytic performance of the reduced catalyst for hydrocracking heptane at 350 and $400{ }^{\circ} \mathrm{C}$. In order to better understand the effect of a GNP incorporation, the calcined NiO-ZY without GNPs was also prepared under the same conditions, characterized, and tested for hydrocracking, after a reduction in $\mathrm{H}_{2}$. A number of conclusive results were obtained from this study:

- GNPs are hydrophobic, and thus they add hydrophobic sites in the composite catalyst, which enhances the affinity between the catalyst and heptane during the reaction, improving its catalytic performance;

- As compared with the reduced NiO-ZY, the reduced GNP/NiO-ZY catalyst results in a $31 \%$ higher conversion percentage at $350{ }^{\circ} \mathrm{C}$ and $6 \%$ at $400{ }^{\circ} \mathrm{C}$;

- The time-on-stream tests revealed that the reduced GNP/NiO-ZY had a significantly better stability with a drop in conversion of less than $2 \%$ after $20 \mathrm{~h}$ of time-on-stream as compared with the $14 \%$ drop in the reduced NiO-ZY; 
- $\quad$ The reduced GNP/NiO-ZY catalyst favored the cracking into lighter molecules, as a high selectivity towards propane was reported. The reduced $\mathrm{NiO}-\mathrm{ZY}$, on the other hand, favored a high selectivity towards iso-butane and n-hexane.

In summary, the composite reduced GNP/NiO-ZY catalyst showed a considerably higher conversion and selectivity as compared with the conventional reduced NiO-ZY, suggesting that carbon-based materials have a promising potential for utilizing them, not only in electrical applications, but also for catalytic reactions such as hydrocracking. The hydrocracking of heptane fuel was selected as a model reaction to test the general suitability of the reduced GNP/NiO-ZY for hydrocracking applications. The hydrocracking of heavier feed molecules shall be tested in the future to further probe the effectiveness of graphene-based composite catalysts in industrially relevant oil upgrading processes.

Author Contributions: Conceptualization, R.S., A.S. and K.P.; methodology, R.S., K.P. and M.A.G.; validation, R.S. and N.C.; investigation, R.S. and N.C.; resources, K.P. and M.A.G.; data curation, R.S. and N.C.; writing-original draft preparation, R.S.; writing-review and editing, K.P., A.S. and M.A.G.; visualization, R.S. and N.C.; supervision, A.S., K.P. and M.A.G.; project administration, A.S.; funding acquisition, A.S. All authors have read and agreed to the published version of the manuscript.

Funding: This research was funded by the Abu Dhabi Department of Education and Knowledge through the ADEK Award for Research Excellence (AARE) 2017, grant number AARE17-270, and partially funded by the Khalifa University of Science and Technology, grant number RC2-2018-024.

Acknowledgments: The authors gratefully appreciate the financial support from the Abu Dhabi Department of Education and Knowledge through the ADEK Award for Research Excellence (AARE) 2017, and Khalifa University of Science and Technology.

Conflicts of Interest: The authors declare no conflict of interest. The funders had no role in the design of the study; in the collection, analyses, or interpretation of data; in the writing of the manuscript, or in the decision to publish the results.

\section{References}

1. Nguyen, M.T.; Nguyen, N.T.; Cho, J.; Park, C.; Park, S.; Jung, J.; Lee, C.W. A review on the oil-soluble dispersed catalyst for slurry-phase hydrocracking of heavy oil. J. Ind. Eng. Chem. 2016, 43, 1-12. [CrossRef]

2. Busca, G. Acidity and basicity of zeolites: A fundamental approach. Microporous Mesoporous Mater. 2017, 254, 3-16. [CrossRef]

3. Dyer, A. Zeolites. In Encyclopedia of Materials: Science and Technology; Elsevier: Amsterdam, The Netherlands, 2001; pp. 9859-9863.

4. Fatima, S.; Singaravel, G.; Hashaikeh, R. Ni-W/nano zeolite Y catalysts for n-heptane hydrocracking. Mater. Chem. Phys. 2018, 212, 87-94.

5. Hashaikeh, R. Insight into ball milling for size reduction and nanoparticles production of $\mathrm{H}-\mathrm{Y}$ zeolite. Mater. Chem. Phys. 2018, 220, 322-330. [CrossRef]

6. Zhuman, B.; Anis, S.F.; Hashaikeh, R. Obtaining high crystalline ball milled H-Y zeolite particles with carbon nanostructures as a damping material. Microporous Mesoporous Mater. 2019, 273, 19-25. [CrossRef]

7. Kazakov, M.O.; Nadeina, K.A.; Danilova, I.G.; Dik, P.P.; Klimov, O.V.; Pereyma, V.Y.; Paukshtis, E.A.; Golubev, I.S.; Prosvirin, I.P.; Gerasimov, E.Y.; et al. Influence of USY Zeolite Recrystallization on Physicochemical Properties and Catalytic Performance of NiMo/USY-Al2O3 Hydrocracking Catalysts. Catal. Today 2019, 329, 108-115. [CrossRef]

8. Martens, J.A.; Verboekend, D.; Thomas, K.; Vanbutsele, G.; Pérez-Ramírez, J.; Gilson, J.P. Hydroisomerization and hydrocracking of linear and multibranched long model alkanes on hierarchical Pt/ZSM-22 zeolite. Catal. Today 2013, 218-219, 135-142. [CrossRef]

9. Verheyen, E.; Jo, C.; Kurttepeli, M.; Vanbutsele, G.; Gobechiya, E.; Korányi, T.I.; Bals, S.; Van Tendeloo, G.; Ryoo, R.; Kirschhock, C.E.A.; et al. Molecular shape-selectivity of MFI zeolite nanosheets in n-decane isomerization and hydrocracking. J. Catal. 2013, 300, 70-80. [CrossRef]

10. Kostoglou, N.; Lukovic, J.; Babic, B.; Matovic, B.; Photiou, D.; Constantinides, G.; Polychronopoulou, K.; Ryzhkov, V.; Grossmann, B.; Mitterer, C.; et al. Few-step synthesis, thermal purification and structural characterization of porous boron nitride nanoplatelets. Mater. Des. 2016, 110, 540-548. [CrossRef] 
11. Birch, M.E.; Ruda-Eberenz, T.A.; Chai, M.; Andrews, R.; Hatfield, R.L. Properties that Influence the Specific Surface Areas of Carbon Nanotubes and Nanofibers. Ann. Occup. Hyg. 2013, 57, 1148-1166.

12. Zhang, L.; Zhang, F.; Yang, X.; Long, G.; Wu, Y.; Zhang, T.; Leng, K.; Huang, Y.; Ma, Y.; Yu, A.; et al. Porous 3D graphene-based bulk materials with exceptional high surface area and excellent conductivity for supercapacitors. Sci. Rep. 2013, 3, 1-9. [CrossRef]

13. Rodriguez-Reinoso, F. The Role of Carbon Materials in Heterogeneous Catalysis. Carbon N. Y. 1998, 36, 159-175. [CrossRef]

14. Lam, E.; Luong, J.H.T. Carbon materials as catalyst supports and catalysts in the transformation of biomass to fuels and chemicals. ACS Catal. 2014, 4, 3393-3410. [CrossRef]

15. Soares, O.S.G.P. Development of carbon materials as metal catalyst supports and metal-free catalysts for catalytic reduction of ions and advanced oxidation processes. Bol. Grupo Esapnol Carbon 2016, 40, $20-23$.

16. Bandosz, T.J. Surface Chemistry of Carbon Materials. In Carbon Materials for Catalysis; Serp, P., Figueiredo, J.L., Eds.; John Wiley \& Sons: Hoboken, NJ, USA, 2009; pp. 45-92.

17. Wong, W.Y.; Daud, W.R.W.; Mohamad, A.B.; Kadhum, A.A.H.; Loh, K.S.; Majlan, E.H. Recent progress in nitrogen-doped carbon and its composites as electrocatalysts for fuel cell applications. Int. J. Hydrogen Energy 2013, 38, 9370-9386. [CrossRef]

18. Boehm, H.-P. Catalytic Properties of Nitrogen-Containing Carbons. In Carbon Materials for Catalysis; Serp, P., Figueiredo, J.L., Eds.; John Wiley \& Sons: Hoboken, NJ, USA, 2009; pp. 219-265.

19. Ng, E.P.; Mintova, S. Nanoporous materials with enhanced hydrophilicity and high water sorption capacity. Microporous Mesoporous Mater. 2008, 114, 1-26. [CrossRef]

20. Kitao, O.; Gubbins, K.E. Theoretical studies on VPI-5. 2. Energy decomposition analysis of the hydrophilicity. J. Phys. Chem. 1996, 100, 12424-12430. [CrossRef]

21. Olson, D.H.; Haag, W.O.; Borghard, W.S. Use of water as a probe of zeolitic properties: Interaction of water with HZSM-5. Microporous Mesoporous Mater. 2000, 35-36, 435-446. [CrossRef]

22. Gianotti, E.; Marchese, L.; Martra, G.; Coluccia, S. The interaction of $\mathrm{NO}$ with $\mathrm{Co} 2+/ \mathrm{Co} 3+$ redox centres in CoAPOs catalysts: FTIR and UV-VIS investigations. Catal. Today 1999, 54, 547-552. [CrossRef]

23. Afanassyev, I.S.; Moroz, N.K. Proton transfer in hydrated ammonium zeolites: A 1H NMR study of NH4-chabazite and NH4-clinoptilolite. Solid State Ion. 2003, 160, 125-129. [CrossRef]

24. Koller, H.; Lobo, R.F.; Burkett, S.L.; Davis, M.E. SiO-...HOSi Hydrogen Bonds in As-Synthesized High-Silica Zeolites. J. Phys. Chem. 1995, 99, 12588-12596. [CrossRef]

25. Oh, J.S.; Shim, W.G.; Lee, J.W.; Kim, J.H.; Moon, H.; Seo, G. Adsorption Equilibrium of Water Vapor on Mesoporous Materials. J. Chem. Eng. Data 2003, 48, 1458-1462. [CrossRef]

26. Jing, M.; Wang, C.; Hou, H.; Wu, Z.; Zhu, Y.; Yang, Y.; Jia, X.; Zhang, Y.; Ji, X. Ultrafine nickel oxide quantum dots enbedded with few-layer exfoliative graphene for an asymmetric supercapacitor: Enhanced capacitances by alternating voltage. J. Power Sources 2015, 298, 241-248. [CrossRef]

27. Gómez, M.J.; Loiácono, A.; Pérez, L.A.; Franceschini, E.A.; Lacconi, G.I. Highly Efficient Hybrid Ni/Nitrogenated Graphene Electrocatalysts for Hydrogen Evolution Reaction. ACS Omega 2019, 4, $2206-2216$. [CrossRef] [PubMed]

28. Regulska, E.; Breczko, J.; Basa, A. Pristine and Graphene-Quantum-Dots-Decorated Spinel Nickel Aluminate for Water Remediation from Dyes and Toxic Pollutants. Water 2019, 11, 953. [CrossRef]

29. Yasin, G.; Khan, M.A.; Arif, M.; Shakeel, M.; Hassan, T.M.; Khan, W.Q.; Korai, R.M.; Abbas, Z.; Zuo, Y. Synthesis of spheres-like Ni/graphene nanocomposite as an efficient anti-corrosive coating; effect of graphene content on its morphology and mechanical properties. J. Alloys Compd. 2018, 755, 79-88. [CrossRef]

30. Dabbawala, A.A.; Tzitzios, V.; Sunny, K.; Polychronopoulou, K.; Basina, G.; Ismail, I.; Pillai, V.; Tharalekshmy, A.; Stephen, S.; Alhassan, S.M. Synthesis of nanoporous zeolite-Y and zeolite-Y/GO nanocomposite using polyelectrolyte functionalized graphene oxide. Surf. Coat. Technol. 2018, 350, 369-375. [CrossRef]

31. Lin, K.Y.A.; Lee, W. Der Highly efficient removal of Malachite green from water by a magnetic reduced graphene oxide/zeolitic imidazolate framework self-assembled nanocomposite. Appl. Surf. Sci. 2016, 361, 114-121. [CrossRef]

32. Khatamian, M.; Divband, B.; Farahmand-Zahed, F. Synthesis and characterization of Zinc (II)-loaded Zeolite/Graphene oxide nanocomposite as a new drug carrier. Mater. Sci. Eng. C 2016, 66, 251-258. [CrossRef] 
33. Gong, P.; Li, B.; Kong, X.; Shakeel, M.; Liu, J.; Zuo, S. Hybriding hierarchical zeolite with Pt nanoparticles and graphene: Ternary nanocomposites for efficient visible-light photocatalytic degradation of methylene blue. Microporous Mesoporous Mater. 2018, 260, 180-189. [CrossRef]

34. Zhang, W.; Tan, Y.; Gao, Y.; Wu, J.; Hu, J.; Stein, A.; Tang, B. Nanocomposites of zeolitic imidazolate frameworks on graphene oxide for pseudocapacitor applications. J. Appl. Electrochem. 2016, 46, 441-450. [CrossRef]

35. Charisiou, N.D.; Papageridis, K.N.; Tzounis, L.; Sebastian, V.; Hinder, S.J.; Baker, M.A.; AlKetbi, M.; Polychronopoulou, K.; Goula, M.A. Ni supported on CaO-MgO-Al2O3 as a highly selective and stable catalyst for $\mathrm{H} 2$ production via the glycerol steam reforming reaction. Int. J. Hydrogen Energy 2019, 44, $256-273$. [CrossRef]

36. Charisiou, N.D.; Papageridis, K.N.; Siakavelas, G.; Sebastian, V.; Hinder, S.J.; Baker, M.A.; Polychronopoulou, K.; Goula, M.A. The influence of $\mathrm{SiO} 2$ doping on the Ni/ZrO2 supported catalyst for hydrogen production through the glycerol steam reforming reaction. Catal. Today 2019, 319, $206-219$. [CrossRef]

37. Kanakia, S.; Toussaint, J.D.; Mullick Chowdhury, S.; Lalwani, G.; Tembulkar, T.; Button, T.; Shroyer, K.R.; Moore, W.; Sitharaman, B. Physicochemical characterization of a novel graphene-based magnetic resonance imaging contrast agent. Int. J. Nanomed. 2013, 8, 2821-2833.

38. Cai, L.; Al-Ostaz, A.; Li, X.; Drzal, L.T.; Rook, B.P.; Cheng, A.H.D.; Alkhateb, H. Processing and mechanical properties investigation of epoxy-impregnated graphene paper. J. Nanomech. Micromech. 2016, 6, 1-12. [CrossRef]

39. Kim, H.; Lee, S. Characterization of electrical heating textile coated by graphene nanoplatelets/PVDF-HFP composite with various high graphene nanoplatelet contents. Polymers 2019, 11, 928. [CrossRef]

40. Viculis, L.M.; Mack, J.J.; Mayer, O.M.; Hahn, H.T.; Kaner, R.B. Intercalation and exfoliation routes to graphite nanoplatelets. J. Mater. Chem. 2005, 15, 974-978. [CrossRef]

41. Brunauer, S.; Emmett, P.H.; Teller, E. Adsorption of Gases in Multimolecular Layers. J. Am. Chem. Soc. 1938, 60, 309-319. [CrossRef]

42. Fagerlund, G. Determination of specific surface by the BET method. Matériaux Constr. 1973, 6, $239-245$. [CrossRef]

43. Barrett, E.P.; Joyner, L.G.; Halenda, P.P. The Determination of Pore Volume and Area Distributions in Porous Substances. I. Computations from Nitrogen Isotherms. J. Am. Chem. Soc. 1951, 73, 373-380. [CrossRef]

44. Langford, J.I.; Wilson, A.J.C. Scherrer after Sixty Years: A Survey and Some New Results in the Determination of Crystallite Size. J. Appl. Crystallogr. 1978, 11, 102-113. [CrossRef]

45. Scherrer, P. Bestimmung der Grösse und der inneren Struktur von Kolloidteilchen mittels Röntgenstrahlen. Nachr. Ges. Wiss. Göttingen 1918, 26, 98-100.

46. Miskolczi, N.; Juzsakova, T.; Sója, J. Preparation and application of metal loaded ZSM-5 and y-zeolite catalysts for thermo-catalytic pyrolysis of real end of life vehicle plastics waste. J. Energy Inst. 2019, 92, 118-127. [CrossRef]

47. Alothman, Z.A. A review: Fundamental aspects of silicate mesoporous materials. Materials 2012, 5, $2874-2902$. [CrossRef]

48. Sing, K.S.W.; Everett, D.H.; Haul, R.A.W.; Moscou, L.; Pierotti, R.A.; Rouquérol, J.; Siemieniewska, T. Reporting Physisorption Data for Gas/Solid Systems With Special Reference to the Determination of Surface Area and Porosity. Pure Appl. Chem. 1985, 57, 603-619. [CrossRef]

49. Chen, N.Y. Hydrophobic properties of zeolites. J. Phys. Chem. 1976, 80, 60-64. [CrossRef]

50. Sharma, P.; Song, J.S.; Han, M.H.; Cho, C.H. GIS-NaP1 zeolite microspheres as potential water adsorption material: Influence of initial silica concentration on adsorptive and physical/topological properties. Sci. Rep. 2016, 6, 1-26. [CrossRef]

51. Zhang, M.; Ma, Y.; Zhu, Y.; Che, J.; Xiao, Y. Two-dimensional transparent hydrophobic coating based on liquid-phase exfoliated graphene fluoride. Carbon N. Y. 2013, 63, 149-156. [CrossRef]

52. Prolongo, S.G.; Moriche, R.; Jiménez-Suárez, A.; Sánchez, M.; Ureña, A. Advantages and disadvantages of the addition of graphene nanoplatelets to epoxy resins. Eur. Polym. J. 2014, 61, 206-214. [CrossRef]

53. Richardson, J.T.; Scates, R.; Twigg, M.V. X-ray diffraction study of nickel oxide reduction by hydrogen. Appl. Catal. A Gen. 2003, 246, 137-150. [CrossRef] 
54. Vakili, M.; Khosrojerdi, S.; Aghajannezhad, P.; Yahyaei, M. A hybrid artificial neural network-genetic algorithm modeling approach for viscosity estimation of graphene nanoplatelets nanofluid using experimental data. Int. Commun. Heat Mass Transf. 2017, 82, 40-48. [CrossRef]

55. Kim, H.N.; Suslick, K.S. The effects of ultrasound on crystals: Sonocrystallization and sonofragmentation. Crystals 2018, 8, 280. [CrossRef]

56. Casimir, D.; Alghamdi, H.; Ahmed, I.Y.; Garcia-Sanchez, R.; Misra, P. Raman Spectroscopy of Graphene, Graphite and Graphene Nanoplatelets. In 2D Materials; IntechOpen: London, UK, 2019; p. 13.

57. Kostoglou, N.; Tzitzios, V.; Kontos, A.G.; Giannakopoulos, K.; Tampaxis, C.; Papavasiliou, A.; Charalambopoulou, G.; Steriotis, T.; Li, Y.; Liao, K.; et al. Synthesis of nanoporous graphene oxide adsorbents by freeze-drying or microwave radiation: Characterization and hydrogen storage properties. Int. J. Hydrogen Energy 2015, 40, 6844-6852. [CrossRef]

58. Gokus, T.; Nair, R.; Bonetti, A.; Bohmler, M.; Lombardo, A.; Novoselov, K.; Geim, A.; Ferrari, A.; Hartschuh, A. Making Graphene Luminescent by Oxygen Plasma Treatment. ACS Nano 2009, 3, 3963-3968. [CrossRef]

59. Charisiou, N.D.; Siakavelas, G.I.; Dou, B.; Sebastian, V.; Hinder, S.J.; Baker, M.A.; Polychronopoulou, K.; Goula, M.A. Nickel Supported on AlCeO3 as a Highly Selective and Stable Catalyst for Hydrogen Production via the Glycerol Steam Reforming Reaction. Catalysts 2019, 9, 411. [CrossRef]

60. Miranda, B.C.; Chimentão, R.J.; Santos, J.B.O.; Gispert-Guirado, F.; Llorca, J.; Medina, F.; Bonillo, F.L.; Sueiras, J.E. Conversion of glycerol over $10 \% \mathrm{Ni} / \gamma-\mathrm{Al} 2 \mathrm{O} 3$ catalyst. Appl. Catal. B Environ. 2014, 147, 464-480. [CrossRef]

61. Charisiou, N.D.; Iordanidis, A.; Polychronopoulou, K.; Yentekakis, I.V.; Goula, M.A. Studying the stability of Ni supported on modified with $\mathrm{CeO} 2$ alumina catalysts for the biogas dry reforming reaction. Mater. Today Proc. 2018, 5, 27607-27616. [CrossRef]

62. Lin, T.J.; Meng, X.; Shi, L. Ni-exchanged Y-zeolite: An efficient heterogeneous catalyst for acetylene hydrocarboxylation. Appl. Catal. A Gen. 2014, 485, 163-171. [CrossRef]

63. Polak, J.; Lu, B.C.-Y. Mutual Solubilities of Hydrocarbons and Water at 0 and $25^{\circ}$ C. Can. J. Chem. 1973, 51, 4018-4023. [CrossRef]

(C) 2020 by the authors. Licensee MDPI, Basel, Switzerland. This article is an open access article distributed under the terms and conditions of the Creative Commons Attribution (CC BY) license (http://creativecommons.org/licenses/by/4.0/). 